\title{
Factors Associated with Men Engagement in HIV Continuum of Care in Rwanda: A Cross Sectional Study to Identify Gaps to be Closed Towards HIV Epidemic Control in Rwanda
}

\author{
Rwibasira GN ${ }^{1,2}$ and Rutayisire $\mathrm{E}^{2 *}$ \\ ${ }^{1}$ Institute of HIV/ AIDS, Diseases Prevention and Control, \\ Rwanda Biomedical Centre, Rwanda, \\ ${ }^{2}$ Department of Public Health, Mount Kenya University, \\ Kigali, Rwanda \\ *Corresponding author: Erigene Rutayisire, \\ Department of Public Health, Mount Kenya University, \\ Kigali, Rwanda
}

Received: June 28, 2021; Accepted: July 15, 2021; Published: July 22, 2021

\begin{abstract}
Despite the global achievements to control HIV epidemic and end AIDS by 2030, there is still a discrepancy in accessing HIV services. Men are among the population that are lagging behind when it comes to consuming available services to mitigate the impact of HIVIAIDS. We conducted this study to determine the level of Rwandan men engagement in HIV services delivery. We used cross- sectional design to analyze data from a Population- based HIV impact assessment, a household-based survey conducted in Rwanda from October 2018 to March 2019. Cascade from awareness of the HIV status, linkage to ART and Viral load suppression were analyzed. Logistic regression analysis was conducted to establish relationship between independent variables and outcomes. Data cleaning and analysis was conducted using SAS 9.4. 13. A total of 821 males aged 15 to 64 years participated in the survey, $302(2.1 \%)$ of them tested positive, $92.2 \%$ (95\% Cl: 89.2-95.2) reported tested once for HIV. Overall, $78.2 \%$ (95\% Cl: $72.4-84)$ reported to be aware of their status and on ART. $70.5 \%$ (95\% Cl: 63.8-77.2) reported to have suppressed viral load. Married or living together with a partner showed to be 7 times more likely to be on ART vs single or never married (OR: $7.42,95 \% \mathrm{Cl}$ : $(1.75 ; 31.38), \mathrm{P}<0.01)$. Odds of viral load suppression increases with age, and those aged above 55 years showed to be more suppressing their virus (OR: 3.94 , (95\% Cl: 0.92-16.9), $\mathrm{P}=0.07)$. Findings from this study revealed the gaps to be closed to include all population in maximizing HIV service delivery.
\end{abstract}

Keywords: Men; Engagement; HIV; Continuum of care; Rwanda

\section{Abbreviations}

RPHIA: Rwanda Population based HIV Impact Assessment Survey; ART: Anti-Retroviral Therapy; VLS; Viral Load Suppression

\section{Introduction}

Globally, UNAIDS estimated 37.9 Million people living with HIV by 2019 [1]. To increase the HIV testing coverage and raise awareness about HIV status and maximize coverage of ART, UNAIDS has set global target for 2020, where by 90 of all PLHIV will know their status, 90 percent of them on treatment and 90 percent of them achieving viral suppression [2]. Among them $81 \%$ of all total PLHIV are aware of their status but only $68 \%$ were accessing anti-retroviral drugs. Despite various strategies put in place to contain the epidemic, Eastern and southern Africa remain the most affected continent with around 54\% of all total PLHIV [3]. Specifically, to this region, effort have been intensified to reduce the AIDS related death by several mechanisms including universal ART coverage, reduction of mother to child transmission, decentralized HIV services delivery to the primary health care and community awareness and engagement of HIV prevention measures [4]. Nonetheless, gender disparity in HIV services uptake is still observed especially in this region with high burden, with men less contributing to the progress [5,6]. Rwanda like other African countries experienced the first case of HIV/AIDS in 1983.

However, several studies conducted in Rwanda during past decade and data reported in fact sheets showed that men category is still lagging in terms of acceptance of HIV services but also engagement in available HIV services [7-9]. The above data showed that prevalence in female is higher than in men $[9,10]$. Level of male testing remains lower compared to female [11]. This affect the whole cascade of continuum of care in Rwanda where male categories always seems to be lower while there are the main key bridge to HIV transmission from the key population to the general population [6]. Various approaches have been put in place to maximize male engagement in HIV testing, including HIV self-testing kit and home testing [12] but the gender disparity remains [13]; hence, the significance of conducting this analysis to evaluate the level of men's engagement and factors associated with this engagement in Rwanda. This study was to determine factors associated with men's engagement in HIV continuum of care from HIV testing, linkage to ART, retention to ART and viral load suppression in Rwanda.

\section{Materials and Methods}

This was a cross sectional study design. It used data from RPHIA, 
a cross sectional household-based national survey. The design of this study has quantitative approaches of data collection. Using interviews and blood draw. Questionnaire was set to design cross sectional study to extract data from testing, linkage to ART and viral load suppression from RPHIA data set conducted between October 2018 and March 2019. The survey has a national representative sample to cover both urban and rural areas countrywide.

\section{Sampling technique}

All men aged 15-64 years participated in the survey were included in the analysis. A two -stage cluster sampling design was used for the primary survey. Within each province, Enumeration Areas (EAs) were selected based on probability proportional to size; the number of households in it defines the size of an EA at the time of the 2012 census. Second stage sampling was consisting of households listing of each selected EA that was updated by NISR. This updated list of HHs (with unique serials identifiers) served as the sampling frame for the selection of HHs in the second stage of sampling. An average of $30 \mathrm{HHs}$ were selected randomly in every EA within each stratum. The selected HHs were visited and there will be no replacements and no changes of the selected HHs will be allowed. The expected number of missing $\mathrm{HHs}$, either by refusal or absence, is already taken into account in the sampling design by increasing the number of HHs surveyed in each EA. During the listing, Global Positioning System (GPS) coordinates of all selected households were collected to help filed staff to identify and relocate sampled HHs during data collection. Males were selected from Household's member's interviews and blood draws.

\section{Data extraction and data analysis}

Data were extracted from RPHIA dataset. Variables were set according to the questionnaires. Preliminary and final reports of the surveys will present descriptive analysis with point estimates and $95 \%$ CI for both prevalence and incidence of HIV infection of key parameters of interest across demographics characteristics as independent variables. Table of variables have been used to populate tables according to variables set to analyze. Independent variables such as age, sex, residence (rural vs urban), marital status, level of education, wealth quantile were analyzed per objectives, from HIV testing, linkage and retention to ART as well as sustained viral load suppression as final outcome in HIV continuum of care. Using bivariate and multivariate logistic regression, relationship with the outcome variable was determined at $\mathrm{P}$-value $<0.05$ and $95 \%$ Confidence Intervals. SAS version 9.4 was used for analysis and to generate tables.

\section{Ethical consideration}

RPHIA survey was approved by Rwanda National Ethical committee (RNEC). In addition, RPHIA was approved in Institutional Review Boards (IRB) in the Human research protection office at Columbia University, New York. The approval to conduct secondary data analysis from RPHIA survey was sought from Mount Kenya University and HIV Division from Rwanda Biomedical center (RBC) which is the owner and direct implementer of RPHIA findings.

\section{Results}

\section{Demographic characteristics of the respondents}

Sample population of this study is presented in frequencies and percentages. From all 13,821 males aged 15 to 64 years participated in
Table 1: Distribution of male adult aged $15-64$ by sex and selected socio demographics characteristics.

\begin{tabular}{|c|c|c|}
\hline Variables & $\mathrm{N}=13,821$ & $\%$ \\
\hline \multicolumn{3}{|l|}{ Residence } \\
\hline Urban & 3,607 & 26.1 \\
\hline Rural & 10,214 & 73.9 \\
\hline City of Kigali & 2,787 & 20.2 \\
\hline South & 2,713 & 19.6 \\
\hline West & 3,226 & 23.4 \\
\hline North & 2,588 & 18.7 \\
\hline East & 2,507 & 18.2 \\
\hline \multicolumn{3}{|l|}{ Marital Status } \\
\hline Never married & 6,635 & 35.3 \\
\hline Married or living together & 6,753 & 35.9 \\
\hline Divorced or separated & 353 & 1.9 \\
\hline Widowed & 74 & 0.4 \\
\hline \multicolumn{3}{|l|}{ Education } \\
\hline No education or nursery & 1,004 & 7.3 \\
\hline Primary & 8,436 & 61.1 \\
\hline Secondary & 3,575 & 25.9 \\
\hline More than secondary & 801 & 5.8 \\
\hline \multicolumn{3}{|l|}{ Age } \\
\hline $15-19$ & 3,072 & 22.2 \\
\hline $20-24$ & 2,226 & 16.1 \\
\hline $25-29$ & 1,874 & 13.6 \\
\hline $30-34$ & 1,788 & 12.9 \\
\hline $35-39$ & 1,573 & 11.4 \\
\hline $40-44$ & 957 & 6.9 \\
\hline $45-49$ & 716 & 5.2 \\
\hline $50-54$ & 595 & 4.3 \\
\hline $55-59$ & 516 & 3.7 \\
\hline $60-64$ & 504 & 3.6 \\
\hline
\end{tabular}

the survey, 3,607 were from urban area and 10,214 were from rural places, representing $26.1 \%$ and $73.9 \%$ respectively. City of Kigali contributed to 2,787 (20.2\%) participants, 2,713 represents $19.6 \%$ from Southern province, 3,226 (23.4\%) from Western Province, 2,588 (18.7\%) from Northern Province and 2,507 (18.2\%) from the Eastern Province.

Among all men aged 15-64 years participated, 22.2\% were between $15-19$ years, $16.1 \%$ between $20-24$ years, $12.9 \%$ between 35-39 years and only 3.6\% aged between 60-64 years. Detailed participants characteristics are presented in Table 1.

\section{Level of HIV testing among men}

Results presented on the below figures reveal that majority of all men around responded about HIV testing. Whereby $75.6 \%$ (95\% CI: 75.1-76.8) of those tested negative for HIV during the survey reported to have at least tested for HIV in lifetime, while only $28 \%$ (95\% CI: 27 29.1) reported to be tested for HIV in the last 12 months. Among all 


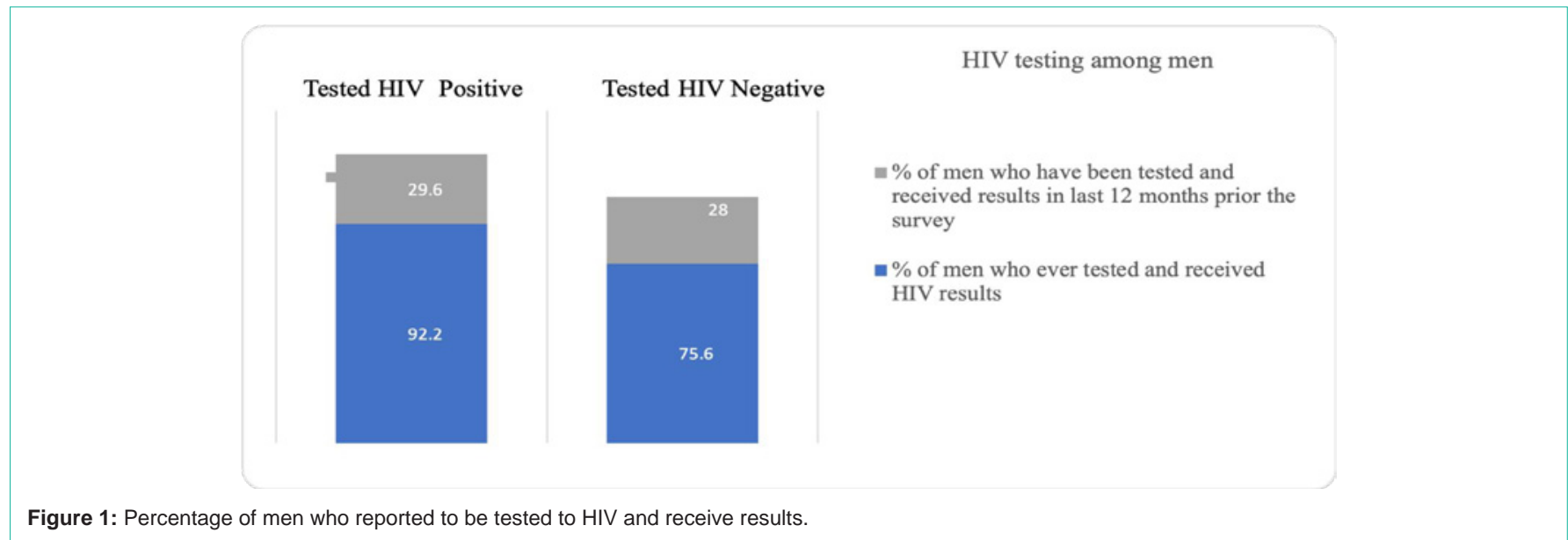

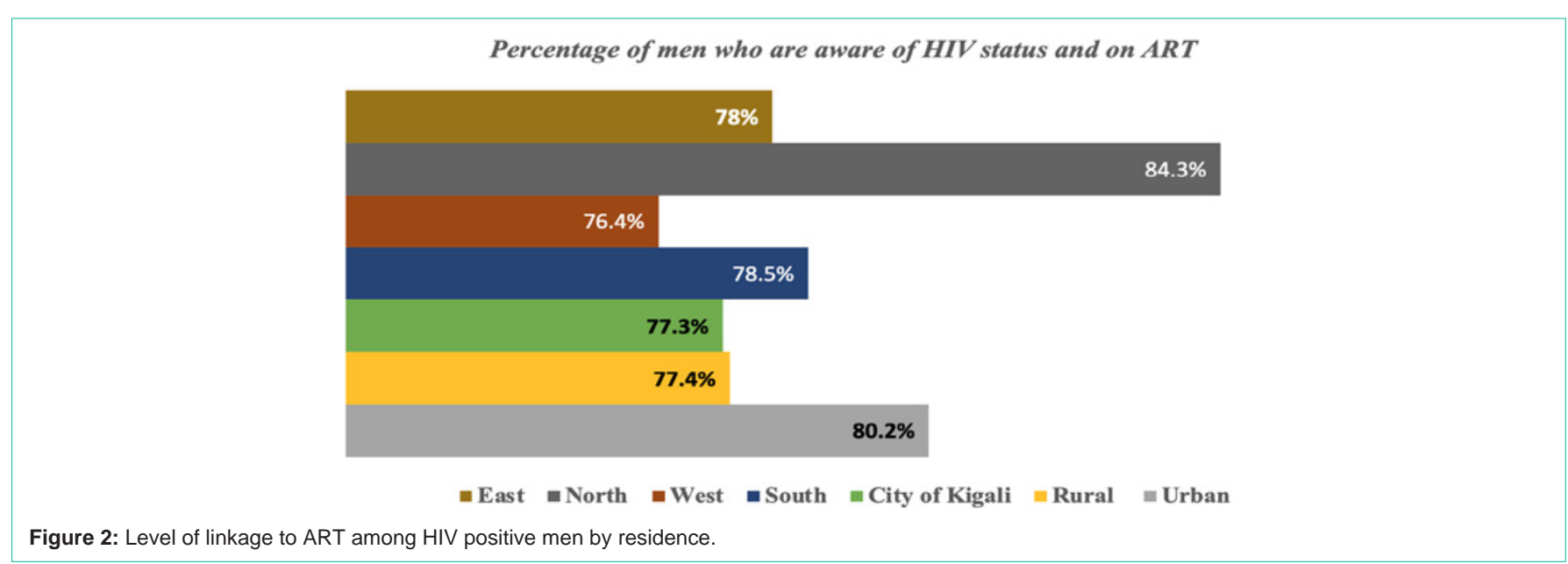

tested positive for HIV during the survey, 92.2\% (95\% CI: 89.2-95.2) reported to have at least tested once for HIV and 29.6\% (95\% CI: 24.3 34.9) reported to have tested for HIV in the last 12 months prior the survey (Figure 1).

\section{Level of linkage to ART among men per residence}

Out of all men tested positive living in urban area, $80.2 \%$ (95\% CI: 71.5-88.8) reported to be aware of their HIV status and on ART, while $77.4 \%$ (95\% CI: 70.2-84.5) of those living in rural area reported to be aware of their status and on ART. Men living in City of Kigali, 77.3\% (95\% CI: 67.8-86.8) reported to have aware of their HIV status and on ART, while $78.5 \%$ (66.6-90.4), 76.4\% (95\% CI: 64.5-88.3), $84.3 \%$ (95\% CI: 73.6-95) and 78\% (95\% CI: 63.4-92.6) are those reported to be aware of their HIV status and on ART from South, West, North and Eastern province respectively.

Generally, among all men aged between 15 to 64 years who tested positive 78.2 (95\% CI: 72.4-84) reported to be aware of their status and on ART (Figure 2).

\section{Viral load suppression among men}

Of all men living with HIV aged between 15 to 64 years in urban areas, $74.1 \%$ (95\% CI: 63.4-84.8) are virally suppressed while among for those living in rural areas, represent 68.9\% (95\% CI: 60.8-77.1). Among men living in City of Kigali, 71.3 (61.2-81.4) of all positive are virally suppressed; while $77.9 \%$ (95\% CI: 65.3-90.4), 74.6\% (95\% CI:
Table 2: Viral load suppression by demographics characteristics.

\begin{tabular}{|l|c|c|c|}
\hline \multicolumn{1}{|c|}{ Variables } & N=302 & \% of VLS & {$[95 \% \mathrm{Cl}]$} \\
\hline Residence & & & \\
\hline Urban & 109 & 74.1 & {$[63.4-84.8]$} \\
\hline Rural & 193 & 68.9 & {$[60.8-77.1]$} \\
\hline Province & & & {$[61.2-81.4]$} \\
\hline City of Kigali & 81 & 71.3 & {$[65.3-90.4]$} \\
\hline South & 60 & 77.9 & {$[62.5-86.6]$} \\
\hline West & 74 & 74.6 & {$[60.1-88.2]$} \\
\hline North & 39 & 74.2 & {$[36.3-63.9]$} \\
\hline East & 48 & 54.3 & {$[35.6-76.1]$} \\
\hline Age & & & {$[63.2-74.2]$} \\
\hline $15-24$ & 26 & 55.9 & \\
\hline $15-49$ & 213 & 65.7 & 70.5 \\
\hline $15-64$ & 302 & & \\
\hline
\end{tabular}

62.5-86.6), 74.2\% (95\% CI: 60.1-88.2) and 54.3\% (36.3-63.9) among men living in South, West, North and Eastern provinces are virally suppressed respectively. Regarding to age categories, out of all men aged 15 to 24 years who are tested positive for HIV, 55.9\% (95\% CI: 35.6-76.1) are virally suppressed, while among those aged 15 to 49 and 15 to 64 years, $65.7 \%$ (95\% CI: $57.2-74.2)$ and $70.5 \%$ (95\% CI: 
Table 3: Factors associated with linkage to ART among HIV positive men.

\begin{tabular}{|c|c|c|c|}
\hline Characteristics $\mathrm{N}=302$ & $\begin{array}{c}\text { Bivariate analysis } \\
\text { OR }\end{array}$ & P-value & {$[95 \% \mathrm{Cl}]$} \\
\hline \multicolumn{4}{|l|}{ Age Group } \\
\hline $15-24$ years (Ref) & 1 & & \\
\hline 25-34 Years & 0.29 & 0.29 & {$[0.029 ; 2.88]$} \\
\hline 35-44 Years & 4.88 & 0.27 & {$[0.29 ; 81.95]$} \\
\hline 45 and more & 3.44 & 0.32 & {$[0.29 ; 40.02]$} \\
\hline \multicolumn{4}{|l|}{ Residence } \\
\hline Rural (Ref) & 1 & & \\
\hline Urban & 2.87 & 0.16 & {$[0.67 ; 12.31]$} \\
\hline \multicolumn{4}{|l|}{ Marital Status } \\
\hline Single/Never Married (Ref) & 1 & & \\
\hline $\begin{array}{l}\text { Married or living together/ } \\
\text { Divorced or separated }\end{array}$ & 7.42 & 0 & {$[1.75 ; 31.38]$} \\
\hline \multicolumn{4}{|l|}{ Wealth Quintile } \\
\hline Lowest/Second (Ref) & 1 & & \\
\hline Middle & 0.33 & 0.38 & {$[0.029 ; 3.82]$} \\
\hline Fourth/Highest & 0.4 & 0.41 & {$[0.046 ; 3.52]$} \\
\hline \multicolumn{4}{|l|}{ Province } \\
\hline \multirow{2}{*}{ Kigali (Ref) } & 1 & & \\
\hline & 0.57 & 0.61 & {$[0.069 ; 4.80]$} \\
\hline
\end{tabular}

63.8-77.2) are virally suppressed respectively (Table 2).

\section{Factors associated with linkage to ART among HIV positive men}

Among all men tested positive, those aged between 35-44 years are 4 times higher linked to ART compared to those aged between 15-24 years and those aged 45 years and above are 3 times higher (OR: 3.44) but no statistical significance observed. Analysis revealed that men living in urban area tend to be more on ART compared to those in urban area, OR: 2.87 95\% CI: $(0.67-12.31) \mathrm{P}$-value $=0.16$, but no statistical significance observed.

Marital status has been showed to be linked to ART among all men who responded. Men who reported to be married or living together showed to be 7 times more likely to be linked to ART compared to those reported to be single or never married, OR: 7.42, 95\% CI: $[1.75 ; 31.38]$, P-Value $<0.001$ in bivariate analysis. Wealth quintile and province of origin did not prove to be significantly associated with linkage to ART among men who participated in the survey (Table 3).

\section{Factors associated with viral load suppression among HIV positive men}

Among all men participated in the survey, those aged 35 years and above showed to be more suppressing their viral load compared to those below. VLS among the men aged 35-44 years showed to be 3 times suppressing their virus referred to those aged $15-24$ years, OR: 3.12, (95\% CI: 0.93-11.1), (P-value=0.07). VLS increases with age, and those aged above 55 years showed to be more suppressing their virus OR: 3.97, (95\% CI: 0.92-16.9), though no observed significance, (P-value=0.07).

Divorced or separated men observed to be 4 times more suppressing their viral load, AOR: 4.0, (95\% CI: 0.72-20.82). VLS was more observed among men reported to be second wealth quintile, OR: 1.69, (95\% CI: 0.29-9.94), P value $=0.23$.

Living in Northern Province was associated with VLS among HIV positive men participated in the survey, OR: 2.27, (95\% CI: $0.75-$ 6.89), $\mathrm{P}$ value $=0.15$, followed by those living in City of Kigali, OR: 1.88, (95\% CI: $0.62-5.74), \mathrm{P}$ value $=0.27$ and those living in southern province OR: 1.05 , (95\% CI: $0.36-3.10)$, P value $=0.92$. However, all factors analyzed for viral load suppression observed to have no statistical significance, $\mathrm{P}$-value $<0.01$.

\section{Discussion}

Findings from this research revealed that men only get tested when they are suspecting any risk of exposure, and men who at least get tested within 12 months are 3 times lower compared to all men at least tested once in lifetime; this may be linked with male perceptions about health seeking behaviors. These findings agree with what reported in the other studies [14-16]. This research showed that men living in urban places, are tend to get tested compared to those in rural area, which was in concordance with other studies conducted in Africa [17-19].

Age was proportionally linked with the level of HIV testing according to findings from this research. Adolescents and young boys representing a big group of study population presented low level of testing rate compared to the rest of adult population; this finding agreed with other studies $[14,20]$. High testing rate was observed among men aged between 30 to 49 years and start declining after 50 years and above, the similar findings were reported in other studies $[21,22]$. The overall testing rate among men in Rwanda was relatively higher comparing to the other countries in sub-Saharan Africa $[23,24]$ but also lower comparing to those reported in Ethiopia and Lesotho [22,25].

HIV positive status awareness and linkage to ART was low among men living in rural places compared to those from urban areas. The findings from this research agree with the other study done in Eswatini [21] but disagree with other findings from other studies done in Zimbabwe and Lesotho [24,25]. Some of the reasons why men in rural places are poor linked to ART explained by the factors that in many African context ,men are usually engaged in the agriculture activities distant to their households and failed to attend the health facilities especially during planting seasons [26,27]. However, in Rwanda, Northern Province (mostly rural) reported to have higher ART retention rate compared to the rest of provinces. Young age was observed to have low rate of uptake to ART as reported in other studies done in Africa [27]. Though level of linkage to ART is low in males according to UNAIDS target [28], is relatively higher compared to the findings reported in other African countries $[21,29,30]$. These are explained by the country coverage and accessibility of HIV services, but mainly the impact of treat all program fast implemented in Rwanda since 2016 to maximize coverage and early ART initiation, which shown to improve significantly on clinical outcome and reduce death among PLHIV [31-33].

HIV viral load was measured to all participants tested positive regardless of use of ART. Men living in rural places reported to have low HIV viral loads suppression in their blood compared to those from urban places, but no statistical significance observed; these 
findings concur with what reported in Uganda [29] but disagree with other study findings done in Africa [21,30]. There is no significance of VLS in rural vs. urban areas in Rwanda. Mainly explained by the universal ART services coverage countrywide, scale up and task shifting of HIV services delivery equally by trained health care providers in rural and urban, early initiation to ART, and effective clinical follow up to enhance adherence $[9,13,34,35]$.

Low percentage of HIV plasma viral load suppression are observed among adolescents and young boys aged 15 to 24 years and higher among men aged 50years and above. The same findings were also observed in other population based surveys $[23,25]$. Overall rate of VLS among men in high in Rwanda compared to other African countries $[2,24,29]$.

Results from this study showed low uptake of HIV services among unmarried males compared to the rest of marital status categories. From testing, uptake to ART and HIV Viral load suppression. The same findings have been also observed in other studies $[30,36]$. Unlikely unmarried men, married, men or living together have more indications to access HIV services, either from accompanying their partners at health facilities, couple testing, family testing and other modalities that involves partners notifications services [37,38]. Most of the unmarried males are adolescents and adults aged 15 to 24 years with risks behaviors sexual practices $[39,40]$ and with low attendance at health facilities. Another reason that can explain the poor uptake of HIV services among young people would be stigma to seek for HIV services, poor experience to HIV/AIDS severity, that lead to poor adherence to ART and low rate of VLS [41-44]. Unlike marital status, findings from this study did not show any significant difference vis a vis engagement of male to linkage to ART and viral load suppression among males who reported to have no formal education compared to the rest of other categories of level of education, the same findings have also reported in other studies [23], but disagree with what reported in Study done in Lesotho [25] which revealed no difference compared to the rest of other categories. Furthermore, regarding wealth quintile and residence, the analysis from this study did not observe any statistical difference among men who participated in the survey. The above findings align with others studies $[45,46]$. The above findings may be explained by the fact that HIV services, including prevention services, testing, and ART prescription in Rwanda have been decentralized in the last 15 years and the maximum coverage. HIV awareness, infrastructures and services delivery are accessible countrywide, though urban places still lead with higher HIV prevalence $[19,28,47]$. However, the above findings disagree with what reported in other countries studies $[23,48]$.

\section{Conclusion}

The recommendations from the World Health Organization state that gender disparities must be acknowledged and addressed if HIV services are to be effective. Difference in HIV services uptake have been identified with growing number of studies highlighting that men are less likely to get tested, to be enrolled and adhere to ART and consequently suppress HIV virus in their blood. The purpose of this study was to study was to highlight demographics characteristics associated with men involvement in HIV continuum of care in Rwanda from the large household national survey. Predictors like rural settings, marital status (single and unmarried) and young age are reported to be linked to the poor engagement on HIV continuum of care in Rwanda. These same factors have also observed in other studies. Findings reported in this study add to current literature and identifying area of interventions to improve on male engagement in HIV continuum of care and help achieving epidemic control.

\section{References}

1. Lozada JS. Joint United Nations Programme on HIVIAIDS. Encycl Glob Heal. 2012.

2. UNAIDS. To help end the AIDS epidemic. United Nations. 2014; 40.

3. Joint United Nations Programme on HIVIAIDS (UNAIDS). AIDS data 2019. Science. 2019; 268: 350-350.

4. UNAIDS. Commitments To End Aids By 2030 Fast-Track Commitments To End Aids By 2030. 2016; 8.

5. Sia D, Onadja Y, Nandi A, Foro A, Brewer T. What lies behind gender inequalities in HIVIAIDS in sub-Saharan African countries: Evidence from Kenya, Lesotho and Tanzania. Health Policy Plan. 2014; 29: 938-949.

6. Seeley J, Grellier R, Barnett T. Gender and HIVIAIDS impact mitigation in sub-Saharan Africa-recognising the constraints. Sahara J. 2004; 1: 87-98.

7. Nsanzimana S, Remera E, Kanters S, Mulindabigwi A, Suthar AB, Uwizihiwe JP, et al. Household survey of HIV incidence in Rwanda: a national observational cohort study. Lancet HIV. 2017; 4: e457-e464.

8. Nsanzimana S, Semakula M, Ndahindwa V, Remera E, Sebuhoro D, Uwizihiwe JP, et al. Retention in care and virological failure among adult HIV+ patients on second-line ART in Rwanda: a national representative study. BMC Infect Dis. 2019; 19: 1-9.

9. NISR. Rwanda Demographic and Health Survey 2014-15 - Final Report. Rwanda. 2015: 640.

10. National institute of statistics Rwanda. Rwanda DHS 2014-15. Kigali. 2016

11. Hepatitis V. Annual Report 2019-2020 1. 2020.

12. Annual HI V. Rwanda National HIV Annual Report. 2016: 1-103.

13. Rich ML, Miller AC, Niyigena P, Franke MF, Niyonzima JB, Socci A, et al. Excellent clinical outcomes and high retention in care among adults in a community-based HIV treatment program in rural rwanda. J Acquir Immune Defic Syndr. 2012; 59: 35-42.

14. Conserve DF, Issango J, Kilale AM, Njau B, Nhigula P, Memiah P, et al. Developing national strategies for reaching men with HIV testing services in Tanzania: Results from the male catch-up plan. BMC Health Serv Res. 2019; 19: 317.

15. Cynthia M. Factors Influencing Men'S Involvement in Prevention of Mother to Child Transmission Services (Pmtct) of HIV Programmes in Gasabo District, Rwanda. A research thesis submitted in partial fulfilment for the award of a master of public health degree. 2008.

16. Morin SF, Khumalo-Sakutukwa G, Charlebois ED, Routh J, Fritz K, Lane T, et al. Removing barriers to knowing HIV status: Same-day mobile HIV testing in Zimbabwe. J Acquir Immune Defic Syndr. 2006; 41: 218-224.

17. MS, CC, CM, ZM, CN, SG. Masculinity as a barrier to men's use of HIV services in Zimbabwe. Global Health. 2011; 7: 13.

18. Conserve DF, Alemu D, Yamanis T, Maman S, Kajula L. "He Told Me to Check My Health": A Qualitative Exploration of Social Network Influence on Men's HIV Testing Behavior and HIV Self-Testing Willingness in Tanzania. Am J Mens Health. 2018; 12: 1185-1196.

19. Survey H. Rwanda. 2014.

20. Siu GE, Wight D, Seeley J. How a masculine work ethic and economic circumstances affect uptake of HIV treatment: Experiences of men from an artisanal gold mining community in rural eastern Uganda. J Int AIDS Soc. 2012; 15: 1-9.

21. Swaziland HIV Incidence Measurement Survey. 2019; 2: 1-257.

22. Report F. Ethiopia Population-based HIV Impact Assessment. 2020. 
23. NACP. Tanzania HIV Impact Survey (This) 2016-2017. Tanzania HIV Impact Surv. 2016-2017. 2018

24. Laboratories L. No Title.

25. Officials TH. Health Impact assessment. 2013; 85: 1217-1222.

26. Camlin CS, Ssemmondo E, Chamie G, El Ayadi AM, Kwarisiima D, Sang $\mathrm{N}$, et al. Men "missing" from population-based HIV testing: insights from qualitative research. AIDS Care - Psychol Socio-Medical Asp AIDS/HIV. 2016; 28: 67-73.

27. Moyo S, Young PW, Gouws E, Naidoo I, Wamicwe J, Mukui I, et al. Equity of antiretroviral treatment use in high HIV burden countries: Analyses of data from nationally representative surveys in Kenya and South Africa. PLoS One. 2018; 13: e0201899.

28. Report F. Rwanda Population-based HIV Impact Assessment. 2020

29. Uganda Population - Based HIV Impact Assessment

30. Malawi Population-based HIV Impact Assessment.

31. Ross J, Sinayobye Jd'A, Yotebieng M, Hoover DR, Shi Q, Ribakare M, et al Early outcomes after implementation of treat all in Rwanda: an interrupted time series study. J Int AIDS Soc. 2019; 22: e25279.

32. World Health Organization. Progress Report 2016 Prevent HIV, test and treat all. Who/HIV/201624. 2016; 64

33. Hoenigl M, Chaillon A, Moore DJ, Morris SR, Mehta SR, Gianella S, et al. Rapid HIV Viral Load Suppression in those Initiating Antiretroviral Therapy at First Visit after HIV Diagnosis. Sci Rep. 2016; 6: 32974.

34. Nsanzimana S, McDermott H, Rhatigan J. HIV Program Scale-Up in Rwanda: 20 years of Experience. 2015; 10

35. Nsanzimana S, Kanters S, Remera E, Forrest JI, Binagwaho A, Condo J, et al. HIV care continuum in Rwanda: A cross-sectional analysis of the national programme. Lancet HIV. 2015; 2: e208-e215.

36. Wolfe DT, Hermanson DR, li BAB, Diri AK, Diri PK, Chotimah C, et al. Educ Psychol J. 2017; 2: 65-72.

37. Katz DA, Kiarie JN, John-Stewart GC, Richardson BA, John FN, Farquhar C Male perspectives on incorporating men into antenatal HIV counseling and testing. PLoS One. 2009; 4: e7602.
38. Aluisio A, Richardson BA, Bosire R, John-Stewart G, Mbori-Ngacha D, Farquhar C. Male antenatal attendance and HIV testing are associated with decreased infant HIV infection and increased HIV-free survival. J Acquir Immune Defic Syndr. 2011; 56: 76-82.

39. Shisana O, Zungu-Dirwayi N, Toefy Y, Simbayi LC, Malik S, Zuma K. Marital status and risk of HIV infection in South Africa. South African Med J. 2004 94: 537-543.

40. Kposowa AJ. Marital status and HIVIAIDS mortality: Evidence from the US National Longitudinal Mortality Study. Int J Infect Dis. 2013; 17: e868-e874.

41. Idele P, Gillespie A, Porth T, Suzuki C, Mahy M, Kasedde S, et al. Epidemiology of HIV and AIDS among adolescents: Current status, inequities, and data gaps. J Acquir Immune Defic Syndr. 2014; 66: 144-153.

42. Fawzi MCS, Ng L, Kanyanganzi F, Kirk C, Bizimana J, Cyamatare F, et al. Mental health and antiretroviral adherence among youth living with HIV in Rwanda. Pediatrics. 2016; 138.

43. Kimera E, Vindevogel S, Reynaert D, Justice KM, Rubaihayo J, de Maeyer $\mathrm{J}$, et al. Experiences and effects of HIV-related stigma among youth living with HIVIAIDS in Western Uganda: A photovoice study. PLoS One. 2020; 15.

44. Kingori C, Adwoa Nkansah M, Haile Z, Darlington K-A, Basta T. Factors Associated with HIV Related Stigma among College Students in the Midwest. AIMS Public Heal. 2017; 4: 347-363.

45. Mishra V, Assche SB Van, Greener R, Vaessen M, Hong R, Ghys PD, et al HIV infection does not disproportionately affect the poorer in sub-Saharan Africa. Aids. 2007; 21: S17-S28.

46. Dokubo EK, Shiraishi RW, Young PW, Neal JJ, Aberle-Grasse J, Honwana $\mathrm{N}$, et al. Awareness of HIV status, prevention knowledge and condom use among people living with HIV in Mozambique. PLoS One. 2014; 9

47. Rwanda Biomedical Centre. National HIV and Viral Hepatitis Annual Report 2018; $1-59$.

48. Peer $N$. The converging burdens of infectious and non-communicable diseases in rural-to-urban migrant Sub-Saharan African populations: A focus on HIVIAIDS, tuberculosis and cardio-metabolic diseases. Trop Dis Travel Med Vaccines. 2015; 1: 1-8. 